\title{
CÂMARA ARDENTE: UM LIVRO?
}

\author{
Francine Fernandes Weiss Ricieri
}

\section{ALGUMAS CONSIDERAÇÕES SOBRE LIVROS SIMBOLISTAS}

Em um texto publicado em 2004, "Livro simbolista, o livro a mais", Vera Lins (2004) traçou uma breve análise de aspectos daquilo que parece implicado na apresentação material do que denominou o "livro simbolista”. Inventariando notas sobre capas, formatos, alternância de cores, associações entre escrita e desenhos, além de outros elementos relativos à apresentação tipográfica, Lins estabeleceu relações entre os aspectos gráficos e formais e a historicidade de constituição desses escritos, sem deixar de assinalar seu potencial de crítica (e resistência?) ao mundo moderno mercantilizado, em sua lógica avessa ao imaginário que essas produções celebrariam. Compondo um volume sobre $A$ historiografia literária e as técnicas de escrita, o texto é, contudo, breve, não chegando a avançar muito no que diz respeito ao modo de organização específica de cada um (ou pelo menos de alguns) dos livros que menciona.

Um levantamento talvez mais completo poderia ser estabelecido percorrendo-se, em exame cuidadoso (e paciente), os dois volumes do Panorama do movimento simbolista brasileiro, preparado por Andrade Muricy (1962). O pesquisador dispersou, ao longo do trabalho, comentários sumários e esparsos sobre livros simbolistas, sem chegar a propor exatamente qualquer questão sobre o livro enquanto estrutura significativa (ou eventualmente, enquanto unidade criativa) nos termos em que ele será abordado aqui. Insere, contudo, ao longo dos verbetes dedicados aos diferentes poetas, indicações sobre a materialidade 
de alguns dos livros, quando tal questão pareça digna de referência, fornecendo dados valiosos no que diz respeito mais especificamente à recuperação do modo de constituição histórica desses escritos.

Assim, se os dois volumes de Muricy mereceram censura pelo que teria sido seu caráter excessivo, sua dificuldade de hierarquização, digamos, qualitativa das obras que referiu, esses elementos podem ser considerados, em contrapartida, uma das mais relevantes contribuições daquele trabalho. Percorrido como repositório documental, o Panorama vai nos revelando detalhes que podem vir a compor reflexões sobre aquela produção. Exemplos seriam as indicações daqueles casos em que a composição gráfica implica o acréscimo de desenhos ou em que há composição conjunta (como entre Félix Pacheco e Maurício Jubim, ou entre Silveira Neto e Gustavo Santiago), com um ilustrando e outro escrevendo. Ou o caso, ainda, de comentários explicativos, como aqueles acrescidos incidentalmente à caracterização do livro Missas Negras, de Xavier de Carvalho: capa preta, com letras prateadas. Em ambos, registram-se "peculiaridades" sobre as quais refletiremos, nas próximas páginas. Já na introdução, o autor indicava a preocupação em documentar a efemeridade de uma produção em vias de desaparecimento, o que desviava o propósito de seu Panorama da mera antologia:

Ficam, por esse modo, senão propriamente salvos, pelo menos aqui refletidos e registrados, numerosos opúsculos, plaquettes, raríssimos, porvezes reduzidos a exemplar único; revistas e jornais de formatos curiosos: losangos ou retângulos alongadíssimos no sentido da altura; composição em caixa alta, num luxo de maiúscula, e impressão a várias cores; ornados de fantasiosas vinhetas e desenhos pretensiosos ou ingênuos, geralmente de deficiente realização técnica (ANDRADE MURICY, 1962, pp. 28-29).

Muricy opta, nesse sentido, por "apresentar o movimento na sua vastidão, na sua complexa rede de correntezas subterrâneas”, o que lhe permite a inclusão de "produções canhestras de um pobre operário torneiro, do subúrbio carioca”, ou ainda, "reconstituições escritas de memória” (ANDRADE MURICY, 1962, p. 29), ou ditadas por contemporâneos. Renunciando, portanto, aos critérios valorativos implicados no conceito de antologia, o Panorama permite a recuperação de um livro como Rosa mística, ou o conjunto dos Tragipoèmes, de Freitas Vale (cada um deles uma junção de breves plaquettes). Ainda a propósito de indicações relacionadas a essas duas referências, ele dispersa, ao longo de suas páginas, inumeráveis indicações de poemas dramáticos, poemas 
narrativos, dramas ou livros em que modos de estruturação hauridos em gêneros dramáticos ou que recorram em maior ou menor grau a procedimentos descritivo-narrativos (ou não líricos; ou lírico-dramáticos ou lírico-narrativos) são atualizados em livros de poemas concebidos como líricos (ou não). Livros simbolistas, nesse sentido, parecem colocar em questão (ou problematizar) certa teoria do poema na modernidade como categoria do lirismo, ou certa teoria do lirismo como única forma concebível do poema no mesmo período, como ocorre nos dois casos mencionados.

Também sem se dedicar de modo sistemático ao problema, em momentos específicos de seu Decadismo e Simbolismo no Brasil, Cassiana Lacerda Carollo (1980-1981) enuncia uma abordagem que muito se aproxima daquela posteriormente desenvolvida por Vera Lins. Em sua "Introdução", faz alusão a aspectos do que seria o "livro simbolista":

O livro, visto como um espaço de significação, é concebido a partir de requintes e busca de novos efeitos: dimensões especiais, lembrando breviários ou iluminuras; exploração dos recursos tipográficos, desenho de letras, emprego de cores, ilustrações participando do texto, vinhetas, apropriação do espaço em branco etc., além da utilização de papeis especiais e previsão de tiragens reduzidas.

Pensando em comparação com as obras realistas e parnasianas, o livro simbolista contrasta imediatamente por suas dimensões, número de páginas, pelo luxo e, consequentemente, seja por exigências previamente deliberadas ou por imposições materiais, pela tiragem reduzida (CAROLLO, 1980, p. XVI).

Juntos, os dois trabalhos apresentam aspectos relevantes do objeto em discussão. Do já mencionado Rosa mística (1900), ${ }^{1}$ Carollo (1980) reproduz o prefácio e Andrade Muricy transcreve um excerto das páginas finais, com comentários sumários no verbete dedicado ao autor. De fato, talvez não tenhamos exatamente a ocorrência do que Andrade Muricy (1962, pp. 674-675) registra como "prosa poética", mas formas e procedimentos relacionáveis ao teatro compostos em verso:

\author{
EGREGOR assenta- \\ do numa pedra, a \\ cabeça entre as mãos,
}

\footnotetext{
1 Observações de Muricy sobre Rosa mística: "Amigo e comentador do ilustre simbolista Pethion de Vilar, Afrânio Peixoto sofreu, por volta de 1900, influência superficial e efêmera do simbolismo, e sobretudo de D’Annunzio, Maeterlinck e Eugênio de Castro, aos quais dedicou o seu 'símbolo trágico' Rosa mística, escrito em prosa poética, e impresso em várias cores e com as características próprias dos livros simbolistas”.
}

Remate de Males, Campinas-SP, v. 37, n. 1, pp. 9-36, jan./jun. 2017 
rememora a vida cruel ...

As sombras des-

filam uma a uma

na escuridão.

EGREGOR

Quem sois? ... Para onde ides?

Vozes enterradas

na treva.

O procedimento não é estranho ao que ocorre entre simbolistas ilustres, mas talvez seja o caso de enfatizar que a criação de uma persona dramática $^{2}$ complexifica as possibilidades significativas dos livros em questão, constituindo-se em problema teórico que mereceria exame mais detido (e que escapa aos objetivos deste ensaio), também por sua recorrência entre poetas brasileiros do período. No caso do livro de Freitas Valle, fica pressuposta, ainda, a inserção da linguagem musical e a apresentação em palco (alguns dos Tragipoèmes podem, de resto, ser pensados como librettos e há registros do espetáculo equivalente, com indicação de músicos e demais envolvidos). Carollo transcreve um texto de Batista Pereira, publicado na Revista Horus (1902), em que o autor oferece uma interpretação e uma origem para o termo tragipoème:

Sabeis que são os Tragi-poemas? São pequenas peças de verso nas quais um caso humano, que impressionou violentamente o autor, é fixado com a nitidez, com a precisão, com a verdade de uma água-forte de Dürer.

O tragi-poema é uma criação de Jacques D’Avray. A sua intuição de Arte ensinoulhe duas coisas. Primeiro: que o coração é a grande fonte da arte verdadeira e que por isso o teatro, esse museu de corações, é a cavilha-mestra da estética moderna. Segundo: que o ritmo do verso é a única expressão dos sentimentos imprecisos, das coisas obscuras, que não se podem traduzir, mas apenas sugerir; de que se não pode dar a imagem, mas apenas a entrevisão. Combinai estes dois princípios de D’Avray: o princípio do teatro e o princípio do ritmo e tereis a explicação artística dos tragi-poemas (PEREIRA apud CAROLLO, 1980, pp. 282-283, grifos do autor).

2 Dominique Combe explorou a presença do que denominou "monólogo dramático ou monodrama lírico" em poemas de Stephanne Mallarmé e Paul Valéry (L'aprés midi d'un faune e La jeune parque, respectivamente). Seu texto "Aimé Césaire et la quête dramatique de l'identité” (RABATÉ, 1996, pp. 177-189) apresenta reflexões teóricas pertinentes para a exploração dos modos de constituição formal tanto de Rosa mística, quanto dos Tragipoèmes, de Freitas Valle. 
É evidente que, no caso de Freitas Valle (que escrevia sob o pseudônimo Jacques D’Avray), essas considerações nos levariam muito longe: talvez ao trabalho de recuperar uma concepção da fatura artística que resiste pouco a delimitações muito estanques, uma concepção historicamente relacionável a experimentos estéticos recorrentes entre simbolistas franceses. Marcia Camargos dedicou um ensaio (2001) à descrição do papel desempenhado pelo mecenas Freitas Valle na vida cultural decadentista brasileira, mas talvez possamos sintetizar sua abordagem histórico-biográfica evocando as aproximações entre Valle e o personagem Des Esseintes, de $\grave{A}$ rebours. A associação foi proposta por Antonio Candido em seu prefácio ao livro de Camargos e foi acompanhada de uma análise do que seria um empenho na estetização da existência, ou da fusão entre arte e vida. Essa fusão teria levado Valle a percorrer um amplo espectro que foi da culinária à música, passando pela poesia e pelo vestuário, bem como à incorporação da pluralidade dessas concepções em interconexão múltipla.

A remissão a Freitas Valle ajuda, ainda, a explorar o fato de que livros simbolistas significam desde a cor da capa até o formato da letra. Podem recorrer, na formulação de seus princípios de coesão: a critérios temáticos, a títulos que enfeixam e coordenam poemas mais ou menos relacionáveis, ao estabelecimento de ciclos ou estruturas cíclicas (como textos seguindo ordensouarranjos numéricos dealgum modosignificativos), à implicitação ou explicitação de estruturas narrativas, à adoção nostálgica de elementos unificadores de natureza genérica ou formal como o trágico ou o épico, à hibridização de gêneros particularizados em outros contextos. Um conjunto de poemas enfeixados em livro pode, ainda, constituir um único poema, como analisaremos na terceira parte deste trabalho: o poema é o livro, ou o livro resulta em poema. Muito recorrente, por fim, é a relação intertextual com outros livros, que passam, em alguns casos, a estabelecer matrizes estruturais para um volume em específico - ou eventualmente dão forma a detalhes da fatura de um dado livro. São numerosas as opções de combinações entre tais possibilidades (ou outras). ${ }^{3}$

\footnotetext{
3 Essas considerações derivam de pesquisa em andamento e partem da observação de um conjunto amplo devolumes que poderiam ser acrescidos a uma reflexão sobre as concepções de livro no período em análise. Menciono alguns: Coroa de espinhos (Archangelus de Guimaraens); Missas negras (Xavier de Carvalho); Vitrais (Lima Campos); Satã (Alves de Faria); Brindes (Nestor de Castro); Carmem (Figueiredo Pimentel); Iluminuras (Érico Curado); Intuições (Saturnino de Meireles); Carrilhões (de Murilo Araújo); além de Atlântida (Dario Vellozo). Em sua maioria raros, os volumes estão disponíveis em acervos específicos. Também se relacionam ao problema, obras de Cruz e Sousa (como Missal
} 
Essa última consideração nos levaria, para citar um caso, ao livro simbolista de Eduardo Guimaraens, A divina quimera. Para além da alusão mais óbvia, indicada no título, Mansueto Bernardi (1944) ocupouse em pensar a organização de $A$ divina quimera em relação com o Vita nuova, de Dante: Eduardo Guimaraens teria reconfigurado, em seu sequenciamento de poemas, a narrativa da história de amor entre Dante e Beatriz. Bernardi lembra, ainda, que a obra se compõe por baladas (poemas narrativos), sonetos e canções. Pela relação com o Vita nuova, A divina quimera implicitaria uma trajetória narrativa, organizada, no entanto, principalmente a partir de uma subjetividade lírica que se constrói de complexas superposições intertextuais. Estudos atualmente em desenvolvimento vêm explorando, ainda, suas relações estruturais com a música, como a tese de doutoramento de Ellen Guilhen, Estrutura e música em dois livros simbolistas de poemas: A divina quimera, de Eduardo Guimaraens, e Sangue, de Da Costa e Silva.

Em 1910, Guimaraens (apud SILVA, 1910, p. 306) publicou no Correio do Povo seu "Discurso sobre a arte", em que propunha uma "compreensão absoluta da vida", a ser atingida por intermédio da poesia (que retomaria seu lugar supremo entre as artes, "irmanadas por um ideal único"). O texto recupera diversos momentos da história da arte em que se proclamou uma nova compreensão da vida e da natureza, na realização de obras múltiplas cujo fim seria "o encorajamento e a glorificação do homem" e entende que a poesia moderna restituiria, pelo ritmo e pela palavra ("instrumentos universais da ideia"), as energias arrancadas à "força passional e tumultuária dos homens" (GUIMARAENS, 1910, pp. 305-307). Maria Luiza Berwanger da Silva, em seu Paisagens reinventadas (1999), recorre a essa publicação para explorar conexões entre o livro de Guimaraens e o Mallarmé de Un coup de dés, explicitando, ainda, demonstrações de interdiscursividade com a música, com a pintura e com a filosofia (em especial com Nietzsche). Essa abordagem parece permitir a inserção, na discussão, de certa apropriação do mito do eterno retorno, que, em diálogo também com Baudelaire, ${ }^{4}$ permitiria ao autor articular sua concepção de busca da beleza como apropriação e recriação da tradição.

\footnotetext{
e Broquéis), de Alphonsus de Guimaraens (em especial Setenário das dores de Nossa Senhora, Câmara ardente e Kiriale), o que vai dito sem pretensões, seja de esgotar uma relação, seja de propor uma tipologia.

4 Em sua alusão a Baudelaire, Silva (1999, pp. 83) recupera especificamente a definição de modernidade discernível no trecho: "La modernité c'est le transitoire, le fugitif, le contingent, la moitié de l'art, dont l'autre moitié est l'éternel et l'immuable" [A Remate de Males, Campinas-SP, v. 37, n. 1, pp. 9-36, jan./jun. 2017
} 
Ao aludir à multiplicidade de tendências, Eduardo Guimaraens mostra o tecido textual de sua reflexão, em que caracteriza a arte nova como arte mesclada. Produto de autores aparentemente distantes, cuja aproximação especifica o ideal de beleza, o discurso cifra-se nesta "volta estética à antiguidade numa modalidade nova [...] novos tipos, diferentes, mas todos prolongando os ciclos da beleza antiga [...]". A insistência na repetição de "nova" e "novas" evidencia o ângulo de transformação criativa. No "Discurso", não se trata de repetir a tradição literária num gesto de celebração, mas, antes, de submeter a memória da leitura ao processo de deformação (SILVA, 1999, pp. 82-83).

Um livro simbolista, nesse sentido, significa por aquilo que nele é mescla, mistura, hibridismo, relativização e reordenação, mas também por aquilo que nele é releitura, atualização, deformação, produção diferida de um novo em cuja carnadura se explicitam sem pudores as múltiplas presenças da tradição. Mescla não só de gêneros, mas também de modalidades estéticas, de posturas enunciativas, de perspectivas e registros díspares. Sobretudo, um tal livro significa pelo modo como as partes de proveniência desencontrada que o compõem de fato integram um novo objeto: um constructo. O prefácio de Rosa mística assim aborda a questão:

A obra de arte deve para durar e para seduzir oferecer uma dupla condição, ter uma ideia que a robusteça como alma, e uma forma que a incarne, vestindo-a exatamente como o corpo. Da desavença desses dois fatores, da ascendência de um sobre o outro, resulta um produto monstruoso, destinado a não viver e a não seduzir, ou a durar, mas a não agradar ou ainda a agradar mas para morrer efemeramente. Sem a ideia que a anime a forma é oca, sem uma forma que a vista a ideia é áspera e intransmissível (CAROLLO, 1980, v. 1, p. 321).

Sem recuperar a divisão dual que, em 1900, agradou ao pensamento do então Júlio Afrânio (Afrânio Peixoto, como o conhecemos), pensaria mais simplesmente na fusão dos elementos, na produção de algo avesso ao monstro. A inserção genérica, a releitura da tradição, a ilustração ou a variedade tipográfica, o vocábulo raro ou alusivo, a construção sintática preciosa ou estilizada, o topos, a imagem coletivamente partilhada, a citação, o nome do outro poeta de que se recuperam valores ou princípios estéticos, cada um dos elementos (sem qualquer precedência por sua eventual origem) passa a compor este livro, esta estrutura significativa, esta unidade de criação.

modernidade é o transitório, o efêmero, o contingente, é a metade da arte, sendo a outra metade o eterno e o imutável] (BAUDELAIRE, 1985, p. 859). 


\section{ALPHONSUS DE GUIMARAENS: LIVROS, PROJETOS, EXPERIMENTOS}

Para examinar mais detidamente Câmara ardente, uma obra de Alphonsus de Guimaraens em que se observam alguns dos sentidos enunciados nas considerações anteriores, seria pertinente recuperar alguns elementos que permitiriam historiar um empenho que talvez não se restrinja à criação de poemas ou outros textos literários. Um empenho que parece considerar pertinente a criação de livros. Tal esforço nos levaria a examinar alguns dos passos por meio dos quais se prepararam os volumes publicados em vida pelo escritor. Sob outra perspectiva, em trabalho anteriormente publicado, examinei alguns desses dados. Recuperandoos, neste momento, passo a perseguir a recorrência de certa concepção de livro (unidade de criação, unidade significativa) disseminada pelos registros de publicação de suas obras poéticas.

Documentos de grande pertinência, nesse sentido, são localizados nos rastros dispersos pela atuação do aspirante a poeta na imprensa. Nascido em 1870, em 1890 Guimaraens cursa Direito em São Paulo, integrando grupos de simpatizantes de tendências simbolistas e decadentistas e divulgando, em publicações periódicas (Novidades, Revista Ilustrada, $O$ Paulistano e $O$ Mercantil) seus primeiros movimentos literários, em companhia de Severiano de Resende, Cruz e Sousa e um extenso grupo de poetas. A dedicação ao jornalismo estende-se ao Comércio de S. Paulo, ao Correio Paulistano, ao Diário Mercantil e a O Estado de S. Paulo.

Por diversas razões, a atividade era decisiva na constituição e coesão dos grupos literários. Garantindo precária profissionalização e meio de sustento, estabelecia e confirmava certo estatuto artístico, sendo, nesse sentido, tão decisivo quanto o ar dândi, com indumentária apurada e troca mútua de incentivos e aconselhamentos literários. Como seus pares, Alphonsus era frequentador do concorrido café intelectual Vechio Leone di Caprera e da preciosa biblioteca de Freitas Valle (o Jacques D’Avray), localizada na Villa Kirial, casarão em que se reuniam para divulgar e desfrutar de literatura e vinhos, tratando-se com longas perífrases francesas, admirando mestres franceses, afrancesando seus próprios nomes, escrevendo versos franceses...

O jovem permanecerá atuante nos jornais paulistanos durante todo o período de permanência na cidade. Em março de 1895, assume o posto de Promotor de Justiça em Conceição do Serro, interior de Minas. Não cessa, contudo, a atividade em jornais, mantendo colaboração com A Gazeta 
(São Paulo). Em 1903, com a supressão do cargo de juiz substituto, por ele ocupado, assume a direção do Conceição do Serro, modesto órgão de divulgação recém-fundado, e produz os textos que o compõem de 20 de março de 1904 até 18 de dezembro do mesmo ano. Depois dessa data, reassumido o cargo de juiz, colabora com o veículo até sua extinção. Transfere-se para Mariana, em 1906. No ano seguinte, já se encontram contribuições suas no jornal local, O Germinal. Contribui também para o Jornal do comércio, de Juiz de Fora, revistas cariocas como Fon-Fon! e $O$ Curvelano, do amigo Álvaro Viana. Por fim, registram-se suas colaborações no jornal humorístico O Alfinete, de Mariana, fundado em 1915.

É certo que sua atuação jornalística contribui para a elaboração de uma poética pessoal e, como não poderei examinar aqui, também com certo empenho na formação dos públicos, o que não chega a ser preocupação exclusiva desse poeta. Entre outros, Alceu Wamosy atuou em jornais desde o início da adolescência, e Emiliano Perneta ficou conhecido por esta atividade: publicou poemas, em 1899, em O Mercantil, O Correio Paulistano e Gazeta de São Paulo, ao lado de Alphonsus de Guimaraens, Wenceslau de Queiroz, Virgílio Várzea e Cruz e Sousa. Associa-se ao nome de Perneta, bem como à divulgação da escrita simbolista, uma extensa relação de revistas e jornais. Em um país com mercado editorial incipiente e concentrado no Rio de Janeiro, tiragens reduzidas e impressas em Portugal e na França, público leitor muito restrito e a maior parte da população formada por analfabetos, as páginas de revistas e periódicos assumiam a tarefa de fazer circularem obras literárias e de disseminar debates, querelas, consagrações.

A questão que se coloca é: como a atuação nos jornais se relaciona com a estruturação de futuros livros? No caso de Guimaraens, talvez ela funcione, antes de mais nada, como laboratório, como exercício, como experimentação. Há informações relativas a pelo menos dois projetos de livros que teriam sido esboçados mentalmente sem eu período deatividade nos periódicos. Esse esboço mental vem registrado em publicações às quais se acresciam os títulos dos livros a que o poema em questão estaria destinado. Nesse sentido, "O cachimbo" (localizado pela primeira vez no Estado de S. Paulo, em 1891) é um poema que apareceria (em sua versão final) no livro Kiriale (1902) e foi originalmente pensado para compor um livro que se denominaria Alucinações.

O projeto nunca chegou a se concretizar, mas o título nos permite sugerir o que nos parecem duas constantes em projetos editoriais de 
Guimaraens. Por um lado, em 1891, sente-se a forte presença de um imaginário decadente, recorrente em muitos dos poemas cuja versão em jornal registra o desejo de um livro, Alucinações, por vezes referido como Das alucinações. O título parece revelar uma constante temática, algo relacionável possivelmente à sugestão de que a percepção do real esteja mais próxima da ilusão, de que tal percepção seja avessa aos mecanismos racionais. O poema "O cachimbo" participaria dessa constante temática, assim como um segundo poema (mais precisamente um grupo de poemas, algumas vezes reunidos sob o título "Memento") destinado ao mesmo livro. ${ }^{5}$

Por outro lado, parece haver aí também o esboço do que será uma recorrente tentativa de estruturação de livros a partir de possíveis constantes formais. Uma delas seria, por exemplo, a marca de organização do também projetado Salmos da noite. Nesse caso, teríamos a inversão valorativa do teor de um salmo: salmos inversos, salmos da noite. Parece que o procedimento evoca pelo menos um livro, não distante cronologicamente, Missas negras, de Xavier de Carvalho (1902), ${ }^{6}$ não sendo de todo distante do que observamos em Missal, de Cruz e Sousa: um gênero discursivo (algo que não se restringe aos gêneros propriamente literários, em suas mais usuais acepções) parece ser apropriado e, de modo mais ou menos livre, redimensionado, funcionando como elemento básico de estruturação da obra em processo de concepção.

O conjunto de poemas que acabou compondo a obra póstuma Pulvis, sob o título "Memento, homo, quia" aparece, igualmente, pela primeira vez em publicações em jornais, com indicação de que viria a compor o livro Das alucinações, como indicam notas preparadas por Alphonsus de Guimaraens Filho e acrescidas à Obra completa de Alphonsus de Guimaraens, de 1960 (p. 712):

O Sr. Antônio Simões dos Reis encontrou este poema publicado in: O Estado de São Paulo (SP, 25 de outubro de 1891) com o título "Memento" e o subtítulo "Das Alucinações"; ainda com a epígrafe:

Pulvis et umbra sumus.

Horatius

\footnotetext{
5 Tanto "O cachimbo" quanto o grupo de poemas "Memento" (bem como o poema "A cabeça de corvo", referido na sequência, e diversos poemas de Salmos da noite) foram objeto de análise em ensaio anterior, em que analiso procedimentos imagéticos recorrentes na obra de Alphonsus de Guimaraens. Por tal razão, considero desnecessário retomar tais análises. 6 Acepção semelhante teríamos também no raciocínio que preside e unifica as Rezas do Diabo, de Wenceslau de Queiroz. Contudo, o livro só foi publicado postumamente, em 1939 .
}

Remate de Males, Campinas-SP, v. 37, n. 1, pp. 9-36, jan./jun. 2017 
Memento, homo, quia

pulvis es, et in pulverem

reverteris.

(Palavras do ritual católico que

o sacerdote diz no dia das Cinzas).

A nota, apenas parcialmente transcrita, indica ainda outras publicações do mesmo grupo de poemas, com apontamento de variantes e explicação da ausência do conjunto em Kiriale, em que mais comumente apareceram aqueles poemas destinados aos dois projetos não concretizados (Alucinações e Salmos da noite):

[...] Publ. também, sem vars., in Jornal do Comércio (Juiz de fora, 12 nov., 1911) com a data "S. Paulo, ano de 1892" e a s. Nota do Autor: "Esta poesia, por haverse perdido, não pôde ser incluída no livro Kiriale, publ. em Portugal em 1902, mas que é cronologicamente a primeira obra do Autor". Publ. ainda em $O$ Germinal (Mariana, 3 dez. 1912) com a mesma data, o título "Memento, homo, quia pulvis es" e sem variantes (GUIMARAENS, 1960, p. 712, grifos do autor).

A escolha da epígrafe transcrita na primeira nota parece reforçar o comentário anterior e igualmente sinaliza processo recorrente em Guimaraens. Aalusão ao ritual católico das Cinzas funciona como princípio de organização do conjunto que, em sua versão final, consiste em uma sequência de quatro poemas unificados pela tonalidade decadente, pelo elemento temático anteriormente descrito e formalmente estruturados, também, por sequenciamento segundo princípios numéricos a partir de uma forma prévia, neste caso o ritual católico do dia das Cinzas. Princípios numéricos, talvez seja o caso de antecipar, são discerníveis também em Câmara ardente e Setenário das dores de Nossa Senhora, mas parecem ter sido igualmente perseguidos na concepção de Kiriale, ainda que, neste último caso, sem os resultados observados nos dois outros livros mencionados.

Um outro poema, "A cabeça de corvo", diz respeito, igualmente, ao mesmo período. Surgiu inicialmente em O Mercantil (3 de outubro de 189o), sendo muito retrabalhado até a versão definitiva. Em 16 de setembro de 1893, aparece na Gazeta de Notícias, com a indicação: "Servindo de prólogo ao livro Salmos, que se acha concluído. - A publicar-se”, em provável alusão a Salmos da noite. Em carta de 20 de julho de 1893, dirigida a Jacques d'Avray, o poema aparece acompanhado da menção "página destacada de Kiriale, prólogo de um livro abandonado" (CAROLLO, 1977, p. 191). 
A hipótese de que os jornais podem ter constituído um laboratório de criação parece reforçada pelo movimento que indicia as hesitações e revisões dos livros em concepção. Tanto Alucinações quanto Salmos da noite não viriam a ser publicados pelo escritor. Kiriale parece ter recebido o que sobreviveu dos dois projetos, em geral poemas reescritos muitas vezes e republicados em datas sucessivas, com muitas variantes. Se os registros indicam que os poemas de Kiriale teriam sido escritos entre 1891 e 1895 , as primeiras versões dos poemas de Salmos da noite seriam relativas aos anos imediatamente anteriores, ou seja, seriam versos da primeira lavra, como aqueles de Alucinações. A diferença entre os dois projetos é que, no primeiro caso, um caderno contendo recortes de jornal teria sido composto pelo próprio poeta, ainda que só fosse publicado postumamente, em 1942, no suplemento Autores e livros (GUIMARAENS, 1942), reaparecendo na Obra completa de 1960. Nota a essa última ocorrência esclarece as condições de sua publicação:

A propósito desses poemas - que são da juventude do poeta - transcrevemos a seguinte nota que acompanhou a sua publicação, por João Alphonsus, no suplemento dedicado ao A. por Autores e livros em 8 nov. 1942:

"D. Maria Guimarães Alvim, tia materna de Alphonsus de Guimaraens, guarda um caderno precioso. A capa desse caderno traz um título - Psalmos da noite - com o nome do autor - 'D’Aff. Guimaraens'. Na última folha, com a letra do Poeta: 'Ouro Preto, 2 de novembro de 1899 '.

São recortes de jornais, ali colados, sem indicações de nomes ou datas.

É essa preciosidade que aqui publicamos.

A indicação - 'Parnaso' - que acompanha os sonetos e as poesias aqui inclusas (que, como o leitor vê, ainda estão assinadas 'Affonso Guimaraes') corresponde à da secção do Estado de S. Paulo, onde esses trabalhos apareceram" (GUIMARAENS, 1960, p. 727).

Se a hipótese for correta, a experimentação (ainda que não tenha sido interrompida até o falecimento do poeta, em 1921) chega a alguns resultados com o fim do período paulistano. Permanecendo em São Paulo até 1895, desde o ano anterior registram-se as primeiras manifestações no sentido de publicar, em formato livro, os poemas que vinha espalhando pela imprensa. Em janeiro de 1894, Alphonsus declara em carta a D’Avray estar preparando a obra Dona mística para publicá-la pela Imprensa Oficial, em Minas Gerais (o que não chega a se concretizar) e, em abril do mesmo ano, anuncia ter escrito o poema "Câmara ardente". Em janeiro de 1896 , envia ao mesmo amigo seu manuscrito pedindo-lhe que faça editar 500 exemplares. Solicita uma tipografia germânica, recomenda que o papel seja de qualidade, sugere caracteres antigos. Chega a enviar 300 
cruzeiros para realizar a operação. Em dezembro de 1896, após um longo silêncio, escreve anunciando seu noivado e suspendendo a publicação. Na mesma carta informa estar compondo o "Poema setenário das dores".

Em 1899 publica, em edição conjunta, Setenário das dores de Nossa Senhora e Câmara ardente (50o exemplares), contendo, na contracapa, a nota:

Embora publicado em primeiro lugar, é este livro, cronologicamente, a terceira obra do autor. Kiriale e Dona Mística, livros escritos de 1891 a 1894, em São Paulo e Vila Rica, serão dados à publicidade quando for da vontade de Deus, em Glória de Quem são feitos (GUIMARAENS, 1899).

Apenas alguns meses depois, também Dona mística era publicado, com tiragem de 250 exemplares:

\begin{abstract}
Magnífica edição da tipografia Leuzinger, Dona mística, a exemplo do Setenário, lembra um livro de orações: a capa é uma sugestiva iluminura e traz em tipo gótico os seguintes dizeres: "Dona mística, poema composto por Alfonsus de Guimaraens [sic], nascido em Vila Rica". [...] "Proficiscere, anima christiana, de hoc mundo Dei Patris Omnipotentis, qui te creavit... - Ano de MDCCCXCIV" (GUIMARAENS, 196o, pp. 32-33).
\end{abstract}

Em 1900, Alphonsus pensará na publicação de Kiriale e solicitará a Jacques D'Avray pesquisar o custo de uma tiragem de 100 exemplares. Revela intenção de que o amigo providenciasse a capa segundo seu gosto, desde que fosse bem litúrgica, com "o perfume de um livro de horas". A obra acaba por ser editada no Porto, apenas em 1902, na Tipografia Universal.

A tais informações acrescentaria a publicidade presente em alguns de seus livros e, em especial, na atividade na imprensa em que se documentam, igualmente, as oscilações dos projetos editoriais: a edição de Mendigos (preparada em 1920, mas que o poeta não chegou a ver) anunciava um livro de sonetos, Pulvis (que acabou por sair postumamente e ao qual os organizadores acresceram outros poemas, além dos sonetos referidos); a última edição do Conceição do Serro traz uma nota anunciando o lançamento (que nunca ocorreu), para "breve", das Crônicas de João Carrilho, em preço "ao alcance de todas as bolsas".

Se a publicidade e os anúncios de projetos denotam a permanência da atividade de estruturação de livros, a preocupação com detalhes gráficos adensa e complexifica os termos em que tais livros (ao menos aqueles escritos em versos) se estruturam: livros de orações ou livros de horas estabelecem estruturas temático-formais, nos termos anteriormente 
descritos. A tais constantes superpõem-se, por vezes, rituais (das Cinzas, ou da Missa de Réquiem, como seria o caso de Câmara ardente). Talvez todas essas considerações forneçam um caminho para a compreensão das eventuais razões pelas quais Salmos da noite ${ }^{7}$ permanece na condição de projeto abandonado (ainda que o caderno encontrado pela família possa indicar o questionamento acerca de sua eventual publicação), ao passo que Alucinações parece nunca ter chegado a se constituir mais solidamente como um livro.

E quanto a Kiriale? Em seu "Vocabulário litúrgico ou atinente à vida religiosa católica, no Simbolismo”, incluído como apêndice ao Panorama do simbolismo brasileiro, Andrade Muricy (1962, p. 1.239) escreve, a propósito do título:

KYRIALE, s.m. Livro litúrgico; contém o Kyrie e o Ordinário da Missa; hoje incorporado ao Missale Romanum. [Título de uma das obras de Alphonsus de Guimaraens].

KYRIE, s.m. Invocação a Deus, enquanto os fiéis se encaminhavam para a Igreja, no cristianismo primitivo [Da liturgia católica. Usado como oração impetratória. Com maiúscula].

Ora, se poemas dos livros abandonados são passíveis de reinserção nesse outro projeto, isso parece se dever ao grau de abertura estrutural de Kiriale. O livro revela o gosto pela temática decadente muito claro nos primeiros versos do escritor, mas não chega a constituir uma fórmula estrutural muito coesa e, nesse sentido, está claramente aquém das conquistas técnicas e formais discerníveis no volume de estreia. Para explicitar o raciocínio ao fundo dessas considerações: parece que a "dobradinha" de 1899 figura como um ponto de chegada, um momento de maturidade que se sucede a um cuidadoso trabalho de busca estética.

Diante desses dois "poemas" (Setenário das dores e Câmara ardente), para recuperar o modo como foram referidos pelo poeta em cartas já

7 Entre outras possibilidades, se recorrêssemos ao pensamento de Gilbert Durant sobre o imaginário e os vários processos de formação de símbolos, poderíamos evocar, por um lado, símbolos associáveis ao que seria um Regime Diurno das imagens (que produziria símbolos ascensoriais, espetaculares ou diairéticos) e, por outro, símbolos associáveis ao que seria um Regime Noturno das imagens, gerador de símbolos de queda, degradação ou decadência. Em Salmos da noite, a locução adjetiva entra em contraste com o que seria o caráter elevado dos Salmos (associáveis a oração, devoção, fé, contrição). Nesse caso, por seu conteúdo e formalização (discerníveis pela leitura dos poemas) temos salmos que remetem diretamente a imagens do que seria um Regime Noturno, sinalizando decadência, degradação, queda (no sentido teológico do termo).

Remate de Males, Campinas-SP, v. 37, n. 1, pp. 9-36, jan./jun. 2017 
citadas e contemporâneas a seu processo de criação, Kiriale e Salmos da noite parecem de fato bem mais precários. O primeiro esboça uma tentativa de fatura temático-formal que resulta problemática (ainda que recorra a partições, numerações, recuperações de fórmulas litúrgicas) e apresenta um conjunto muito desigual de poemas, visivelmente coligidos para o livro (o que se documenta facilmente com recuperação dos dados relativos à atividade em jornais e periódicos). Também não se encontra bem arranjada, nesses projetos, a obsessão pelas estruturas sequenciais.

Em livro de 1956, Fausto Cunha e Waltencir Dutra descreviam Guimaraens como um poeta extremamente sensível às formulas encantatórias da linguagem eclesiástica. E Henriqueta Lisboa (1970), uma das mais consistentes leitoras de Guimaraens, apontou em sua poesia o gosto da forma repetitiva, das proporções regulares e do equilíbrio aritmético, a correspondência entre as partes que se articulam com o motivo propulsor de uma obra, a necessidade de ordem obtida pelo estabelecimento de simetrias, por imagens paralelas e pelo recurso a uma simbologia numérica de fundo místico. $\mathrm{O}$ fato é que nem Kiriale nem Salmos da noite permitiriam sustentar plenamente as afirmações de Lisboa ou de Cunha e Dutra - mesmo que nenhum desses críticos esteja pensando a questão do livro nos termos do presente texto.

Em que difere, então, a primeira publicação? Antes de mais nada, pelo modo como o interesse pela liturgia aí aparece enquanto elemento estrutural da obra (e não como mera incidência vocabular ou temática), o que está demonstrado em um estudo recentemente publicado e que se dedica a uma leitura do Setenário das dores de Nossa Senhora (VERAS, 2016). Ressaltando a presença no livro de uma estrutura em si mesma significativa, o trabalho associa sua arquitetura à forma do oratório musical, analisando não apenas a estruturação das partes que compõem o volume (sete seções emolduradas por duas composições: uma de abertura e outra de encerramento), mas também a configuração discursiva dos poemas.

Quanto a este último aspecto, aponta a convergência estrutural de vozes que recuperariam diretamente a narrativa bíblica (vozes com função narrativa) e vozes que meditariam sobre seus episódios, principalmente sobre a impotência de vivenciá-los por intermédio da linguagem (associáveis à lírica). Essa configuração discursiva aproximaria o livro da forma dos oratórios musicais, em que teríamos o recitativo (que recupera a narrativa bíblica) e as árias e corais (em que se registraria a celebração 
da história sagrada por meio dos comentários e impressões poéticas do autor).

Para Veras, em sua formalização híbrida, a forma poética do oratório remeteria à fragmentação de um sujeito poético para o qual a experiência mística se apresentaria frustrada, o que permitiria a representação poética de uma das mais tradicionais celebrações litúrgicas do catolicismo (a celebração das Dores de Nossa Senhora) em uma arquitetura litúrgica de grande modernidade, o que se poderia reforçar pelas aproximações estabelecidas no trabalho entre Alphonsus de Guimaraens e Baudelaire, ou, de um modo mais geral, pelo modo como o livro vai gradativamente realizando esforços no sentido de reaproximar o trabalho do escritor da consciência poética que lhe é contemporânea. Nas palavras de Veras (2016, p. 110), uma "vivência particular e incomparável da agonia que caracteriza a poesia de seu tempo".

\section{CÂMARA ARDENTE: UM LIVRO?}

Ao contrário do que ocorre com Kiriale, os documentos disponíveis sugerem que Câmara ardente teria sido composto como uma unidade: como um poema. Por volta de 1953, o escritor Martins de Oliveira teria localizado no espólio de Álvaro Viana seus manuscritos (GUIMARAENS FILHO, 1953, p. 2), que permitem estabelecer as alterações impostas à versão final e indicam como data de composição a Quaresma de 1895, período que coincide aproximadamente com o ponto de chegada que indicávamos anteriormente. Também como poema, Guimaraens se referia ao futuro Setenário das dores.

Embora a tradição crítica costume abordar cada um desses conjuntos como livros publicados em edição composta, a nota do autor que antes transcrevemos refere-se a um único livro, que, em sua capa, indica os dois títulos e acresce, abaixo, “poemas”. É certo que há, no conjunto, ao menos os quatorze poemas que compõem Câmara ardente e mais os cinquenta e um que integram o Setenário ("Antífona”, sete seções denominadas “Dores", contendo cada uma sete sonetos, e "Epífona"). Examinaremos, contudo, os sentidos que parecem advir da hipótese de uma unidade ainda mais imbricada entre as peças que compõem cada um dos conjuntos, o que parece sugerido por conotações deriváveis do emprego do termo "poema", em um e em outro caso. 
Estruturando-se a partir de uma espécie de paráfrase da liturgia dos mortos (fica situado o leitor, na abertura dos versos, diante ou no interior de uma câmara ardente em pleno ritual mortuário), o poema em questão aciona outras matrizes compositivas (ou ritualísticas) que confirmam ou complexificam aquela primeira referência: epitalâmio, elegia, epicédio, nênia, réquiem, responso, via-sacra, salmos. Acompanha-se, ainda, de epígrafes latinas que, em posições estratégicas, explicitam a alusão litúrgica e, paralelamente, declara-se "canto" já no soneto de abertura (que enuncia, ainda, um projeto, um conjunto de pressupostos implicados na consecução desse mesmo canto, referido, ainda, como "poema de Amor").

Sérgio Alves Peixoto, em seu livro A consciência criadora na poesia brasileira (1999), explora aspectos da composição do Setenário e de Câmara ardente, contrapondo o que seria o problema propriamente místico (a condição submissa do homem em face do divino) ao que seria o problema metapoético (a condição submissa do poeta em face de sua linguagem). O projeto estético complexo reforçaria a reflexão sobre o literário, ou as reflexões sobre o literário em curso no final do século XIX. O poema que introduz o leitor à câmara em que se vela a morta a ser acompanhada até o sepultamento, "Peristylum", funcionaria, segundo essa lógica, como pórtico do projeto poético a se desenrolar. Como assinalou o ensaísta, a forma latina propiciaria o estranhamento que teria marcado a linguagem simbolista, acrescendo, ainda, uma conotação de sacralidade que prepararia a operação de autoinserção no templo em ofício.

Como sugeri em outro ensaio, em conclusão que se relaciona também ao que se desenvolve neste texto, o poema constitui, ainda, o pórtico do primeiro livro de um escritor que, preterindo outras obras já concluídas, oferece ao leitor uma marca de início de percurso, uma proposta de projeto literário. A imagem do peristilo, corredor pelo qual se adentra um templo atravessando uma fileira de colunas, parece coerente também com esta outra conotação: os versos remetem, nesse sentido, a imagens de silêncio, isolamento e precariedade a que se parece contrapor uma operação de que resultam os versos em escrita, "extremo Epitalâmio augusto". Apresentase, assim, ao leitor, uma poesia associada à quietude e ao mistério, em uma espécie de ritual em que se encontram, como noivos em celebração, ainda na leitura de Peixoto (1999, pp. 335-337), poesia e morte:

Mas o que é essa "perfeição astral”, esse "Eterno-Voto", entre outros símbolos, senão uma espécie de máscara sugestiva da divina posse da poesia, não racionalmente exposta como trabalho, mas intuitivamente sentida como graça 
e comunhão com o mistério? No poema de Amor de Alphonsus, o recinto sagrado do poema e o clima silencioso em que deve reinar a oração fazem parte essencial do grande momento de inspiração e realização poéticas que irão determinar a perfeição da obra.

Ainda que acompanhando os raciocínios de Peixoto, assinalaria outro movimento presente na sequência de poemas: um movimento por meio do qual seguimos uma operação que se desenrola no tempo. Após adentrar uma Câmara ardente que se oferece simultaneamente enquanto ofício dos mortos e celebração do poético, será preciso percorrêla, acompanhando os próximos doze passos, aos quais se seguirá um significativo "Responsorium", em percurso eminentemente narrativo. Assim, o "Soneto I", posterior a "Peristylum", oferece ao leitor a primeira visão da morta que se vela:

Ei-la afinal exposta à benção dos Altares,

E a morte que a matou é a mesma de que morro...

Chamou-vos para o Céu, pobres, pobres olhares,

A voz pungente de Jesus do Bom-Socorro!

(GUIMARAENS, 196o, p. 129)

A amada morta, ainda que se observem verbos em diferentes registros temporais, encontra-se presentificada diante do observador. A estrofe se abre em demonstração ("Ei-la"), expondo um corpo à contemplação e formulando, em acréscimo, uma perspectiva lírica que a tensiona: "E a morte que a matou é a mesma de que morro..." (GUIMARAENS, 1960, p. 129). Um sujeito se enuncia, portanto, enquanto enuncia as presenças pungentes da morta e da morte. Nesse soneto como um todo, de resto, parecem predominar as expressões difusas de dor e de pesar ("Nuvens de oiro e de bronze: horas crepusculares, / Roxas de som, beijando a Cruz no alto do Morro: ...”; p. 129), que assim se apresentam nos tercetos finais:

Ei-la afinal exposta à bênção de Onde veio.

Sinto o silêncio das ermidas e dos ermos,

Uma saudosa paz de esperança e de anseio...

Foi-se morrendo (e o meu amor nem deu por isso)

O amortecido olhar dos seus olhos enfermos ...

Dona Mística, flor-de-lis, sol outoniço!

Ressaltar a presença de uma voz cuja dor ou cujo luto acompanha a exposição do cadáver oficiado permite a preparação para um contraponto com o que se poderá observar nos sonetos seguintes. Esse soneto 
primeiro recupera o processo de fenecimento da amada, assinalando simultaneamente a presença de um parceiro amoroso que oscila entre o desengano, a saudade e, em especial na primeira estrofe, certo desespero. Será o poema em que a presença de uma subjetividade afrontada pela morte se marca de modo mais intenso. Nos posteriores, o que se observa é o gradativo desaparecimento dessa voz em luto, dessa marcação de angústia chorosa, em favor de uma dicção cada vez mais serena.

No Soneto II, esse movimento já se delineia:

Voltas a ser de novo aquilo que tu eras.

A evocadora palidez do teu semblante

Faz-me pensar nas Virgens-Monjas de outras eras,

Quando de nós estava o Céu menos distante.

Na áurea correspondência estelar das esferas

A tua Alma nupcial há de passar triunfante.

$\mathrm{O}$ teu olhar reflete, entre vagas quimeras,

O Inferno, o Purgatório e o Paraíso de Dante.

Havia tal palidez ao redor do teu vulto,

Que eu disse ao ver-te aqui, nas terrenas idades:

O teu corpo já esteve entre flores sepulto...

Nesses restos de vida arde um fogo celeste:

Passam no teu olhar as longínquas saudades

Do esquife que deixaste ou do Céu de onde vieste...

(GUIMARAENS, 1960, p. 130)

Ao contrário do que ocorre no soneto anterior, no qual se recupera o processo em que se chega à morte (incomodamente flagrada, portanto, ainda em hipótese, em devir), com o sujeito sentindo o silêncio, ou morrendo junto com a amada, o Soneto II se abre com um verso que parece evocar o memento da liturgia das Cinzas: volta a figura feminina ao pó de que foi feita, volta a ser o que era. A amada aparece em sua palidez extrema, convertida em abstração. Na primeira estrofe, persistem duas indicações que remetem a essa voz que se enuncia: na primeira, a palidez feminina "faz-me pensar" nas Virgens Monjas de outras eras (versos 2 e 3). Na segunda, o quarto verso recorre a um "nós" que converte ao plural, coletivizando, a sugestão de cisão entre subjetividade e transcendência.

De todo modo, o sujeito que aí permanece perdeu a pungência discernível no Soneto I, e a descrição da morta ou da morte converte-se em tema literário: correspondências, quimeras, alusões dantescas, vagas reminiscências camonianas. No primeiro terceto, esse "eu" que "diz" é tão 
distanciado quanto aquele que, no primeiro quarteto, "pensa” em Virgens Monjas. Permanece o leitor na câmara ardente, enquanto a transição da subjetividade enlutada para a celebração ritualística distanciada encontrase em operação, ainda que o Soneto III realize um recuo, um retorno à doença è amada moribunda:

\footnotetext{
Na tua Alma imortal, como sombras no poente, Vinham chorar de noite espectros visionários... E sempre erguido para Deus o olhar vidente, Esperavas com a fé dos Anjos Solitários.

Via dentro de mim o teu fantasma doente, E a longa procissão dos sonhos tumultuários: Eram visões chorando miserandamente, E sem coragem de subir tantos Calvários. (GUIMARAENS, 1960, p. 130)
}

Parecehaverumcontraste:o Soneto I seencerrava poruma enumeração alusiva à morta, enumeração que se coroava por uma exclamação. No Soneto III, recupera-se o enamorado obcecado pelo "fantasma doente" e por seus "sonhos tumultuários", confrontado com a morte iminente e todo o conjunto de imagens pressagas do primeiro quarteto. No entanto, no terceto final, a morte pode ser constatada de modo quase lasso: "E eu disse ao contemplar-te: Uma Cruz se levanta / No fim da estrada azul por onde tu caminhas" (GUIMARAENS, 1960, p. 130). Observamos, de resto, ao longo dos sonetos IV a X, um progressivo apagamento dessa voz que se enuncia, no movimento de recuos e avanços de um poema organizado segundo uma estruturação narrativa:

VIII

A Cruz que beijas traz o roxo véu apenso, Pois foi no tempo da Paixão que tu seguiste A via-sacra que vai da terra ao Céu imenso:

E Deus, crucificado, olhou-te sempre triste.

Enublam-se pelo ar as coroas do incenso...

E na hora de seguir para onde o Amor existe

Em luz, hás de rever, como num sonho intenso,

Tudo quanto sonhaste e tudo quanto viste.

O Sacerdote toma o sagrado aspersório

Para benzer-te em cruz: choram dentro da alcova

As almas dos infiéis temendo o Purgatório. 
Fulge um clarão por entre os rumores da prece,

E uma inefável voz de Anjo excelso a Deus louva;

É uma alma que sobe, é a Absolvição que desce...

(GUIMARAENS, 1960, p. 132)

A cada novo soneto dados novos são acrescidos ao conjunto, como a alusão ao período da Paixão, marcador temporal do início da trajetória percorrida pela personagem central. Retomam-se, em nova perspectiva, os dias extremos da enferma, bem como referências literárias anteriormente acionadas. E a presença do Sacerdote, na terceira estrofe, assim como a imagem da cruz sobre os lábios do cadáver remetem à continuidade de uma ação que se encaminha para um desfecho. O soneto em leitura retoma os anteriores, que ao mesmo tempo retoca e complementa. E, em relação aos quais ora avança, ora recua: o movimento não é linear, nem é preciso que o seja. Há, contudo, um movimento para o qual importam tanto as progressões quanto as permanências, tanto o que se altera quanto o que marcadamente recorre.

O texto parece recuperar, nesse sentido, a tradição de poemas narrativos que poderiam, em grande salto, ser associados à épica, mas que não se restringem ao alcance histórico daquele termo. Entender Câmara ardente como um poema pode levar a pensá-lo, então, a partir da tradição do poema longo, ou do poema narrativo longo, com repercussão importante nos séculos XIX e XX. Essa seria a perspectiva (a da relevância de uma tal modalidade de fazer poético) de Dominique Combe (2008), em uma conferência originalmente intitulada "La nostalgie de l'épique", em que examina ainda aspectos paralelos à recusa teórica de uma eventual presença do épico e de suas transformações na Modernidade, como o estabelecimento e manutenção de certa tradição de dissociação entre poema e narração. Combe atualiza, ainda, algumas reflexões sobre o "poema longo" (também estudado por Octavio Paz, 1993), bem como possibilidades de coexistência entre narratividade e uma específica manutenção do lirismo.

8 Dominique Combe proferiu conferência intitulada "La nostalgie de l'épique", também publicada sob o título "L'épopée à l'époque moderne" (COMBE, 2008). No texto, recupera formulações de Hegel, Lukács e Bakhtin (que encontraram no romance a forma historicamente possível e para a qual teriam sido convertidas as epopeias, na sociedade burguesa) para examinar a trajetória histórica do épico no Ocidente, chegando a poetas como Saint-John-Perse, Pound, Glissant, entre muitos outros, e reputando como pertinente a manutenção da discussão se não da epopeia, ao menos da "questão do épico" e da permanência de padrões narrativos em poesia.

Remate de Males, Campinas-SP, v. 37, n. 1, pp. 9-36, jan./jun. 2017 
Para explorar a questão, o autor recupera o termo poema em referência a textos com unidade de composição, constituídos como ficções poéticas, com cenário e personagens (mesmo que eventualmente abstratos) e, sobretudo, com manutenção da função narrativa, em maior ou em menor grau. Estaríamos diante de um gênero que reuniria o lírico e o épico (ou narrativo), eventualmente mesmo o dramático, e que manteria, no horizonte analítico, a questão teórica da constituição do sujeito lírico. Em publicação anterior, Poésie et récit: une rhétorique des genres, Combe (1989) já demonstrara como a descrição crítica da poesia da modernidade teria cristalizado uma oposição teórica entre a "poesia moderna" e outras formas como o drama, descrição e, sobretudo, narração. Assinalando a presença do récit em Baudelaire (bem como na tradição poética que lhe é anterior), Combe (1989, p. 10, grifo do autor) defende, nesse livro, ter havido, a partir de Mallarmé e Rimbaud a proposição de uma nova "retórica dos gêneros literários", para a qual a exclusão do narrativo seria aspecto decisivo:

L'exclusion du narratif prononcée par les poètes dans leurs essais et commentaires a fini par s'imposer comme une évidence: de sorte que les critiques, les rhétoriciens et les poéticiens eux-mêmes ont interiorisé la "distance" entre la poésie et le récit, désormais perçus comme incompatibles. Un des presupposés essentiels - impensé, comme tel - du discours critique sur la poésie est que celle-ci se différencie du récit par nature. C'est dire qu'il est nécessaire d'inclure dans le corpus, outre les manifestes et les déclarations des poètes, les commentaires et les meditations de certains critiques ou essayistes qui ont largement contribué à imposer au prés des lecteurs, aussi bien que des écrivains, une nouvelle rhétorique des genres littéraires. L'exclusion du narratif, d'abord posée comme une exigence propre à quelques poètes, est devenue partie integrale du paysage poétique contemporain: c'est bien à un système des genres que conduit le refus du récit en poésie. ${ }^{9}$

\footnotetext{
9 "A exclusão da narrativa defendida pelos poetas em seu ensaios e comentários acabou por se impor como uma evidência: de tal modo que os críticos, os retóricos e os próprios poetas interiorizaram a 'distância' entre a poesia e a narração, a partir de então consideradas incompatíveis. Um dos pressupostos essenciais - ainda que não pensado como tal - do discurso crítico sobre a poesia é que esta se diferencia da narração por natureza. O que equivale a dizer que é necessário incluir no corpus, além dos manifestos e das declarações dos poetas, os comentários e as reflexões de alguns críticos ou ensaístas que contribuíram largamente para impor aos leitores, assim como aos escritores, uma nova retórica dos gêneros literários. A exclusão da narrativa, inicialmente colocada como uma exigência própria a alguns poetas, tornou-se parte integral da paisagem poética contemporânea: pois é realmente a um sistema de gêneros que conduz a recusa da narração em poesia."
} 
Em Poésie et récit podem ser observados dois movimentos teóricos: o de explicitar os pressupostos desse "sistema de gêneros" (viabilizado pela generalização de traços de um específico objeto poético, aquele passível de ser associado, de algum modo, ao que se costuma denominar "poesia pura”) e o de estabelecer as relações entre poesia e narração em poemas da modernidade. O segundo interessa mais diretamente a este texto, para o qual precisamente a inserção de Câmara ardente em uma tradição narrativa constitui elemento indiciador de sua modernidade. Mas as reflexões de Octavio Paz (1993) sobre o "poema longo" já haviam indicado algumas questões que contribuiriam para o que aqui se esboça. Em especial sua consideração de que o poema longo seria regido pelo duplo princípio da variedade e da unidade: a máxima variedade estruturada em unidade, para o que concorreriam a surpresa e a recorrência. Recorrência, em poesia, iria do metro ao acento, da rima às retomadas de motivos, temas musicais, assonâncias, anáforas e marcas de continuidade.

Em Câmara ardente, a recorrência começaria na forma comum a treze dos quatorze poemas: sonetos. A surpresa estaria na novidade formal do derradeiro. A recorrência poderia ser perseguida nas imagens, no arcabouço sonoro e rítmico, além das incidências vocabulares indiciadoras de obsessões do enamorado (palidez, olhar, Alma, Altares), sendo surpreendentes os novos ângulos, os recuos, a forma peculiar que cada quarteto ou terceto encontra para redimensionar o mesmo tema do amor frustrado pela morte. Também em "Responsorium", que encerra o conjunto, as recorrências se fazem acompanhar de diversos elementos que revelam seu complemento (como pensado também por Octávio Paz) - a ruptura, a mudança, a invenção e o inesperado. Tudo pertencente ao campo da surpresa:

Responsorium

Alma que teve quem dela se recordasse

Na ignóbil terra infiel onde tudo se esquece:

Requiescat in pace.

Corpo a esperar que o Noivo-Esperado chegasse,

Rosa autunal que o sol do Amor não mais aquece:

Requiescat in pace.

Olhar que se apagou sem que nunca pecasse,

Ciliciado Altair que entre luares floresce:

Requiescat in pace. 
Lábio que dera a quem neste mundo a beijasse

A luz espiritual de uma longínqua prece:

Requiescat in pace.

Beijo, fruto estival que lhe floriu na face,

Evocador de tão prometedora messe:

Requiescat in pace.

Cabelo, pôr do sol que entre neves brilhasse,

Nuvem dispersa além quando a tarde anoitece:

Requiescat in pace.

Alma que teve quem dela se recordasse

Na ignóbil terra infiel onde tudo se esquece:

Requiescat in pace.

(GUIMARAENS, 1960, p. 135)

"Responsorium", o único poema que não se formaliza como soneto, é o primeiro a ser construído por espelhamento entre as estrofes. Que, sendo sete, divergem do padrão estrófico dos sonetos, mas de algum modo remetem à equação numérica do conjunto: treze poemas de quatorze versos arranjados em quartetos e tercetos; um poema final com quatorze versos arranjados em dísticos + refrão. Sete estrofes que se espelham rigorosamente entre si. De estrutura inesperada, Responsorium coroa o andamento ritualizante que o antecedeu e que, de algum modo, corrobora. Sua formulação coral (prevista já no título latino) faz supor a assembleia reunida no momento derradeiro do ofício fúnebre - permitindo supor, em acréscimo, o que seria a expressão final da voz que se arrefeceu à medida que os sonetos se sucediam. Vinham recorrendo formulações que deslocavam a primeira pessoa do singular para a primeira do plural. Vaga reminiscência de coro trágico, o poema final desvia de modo mais rigoroso o acento da subjetividade para a coletividade e projeta na consciência de grupo, escorada no poder da fórmula, o deslocamento da dor pessoal para a constatação grupal da inevitabilidade da morte. E as estrofes inicial e final de Responsorium são e não são idênticas entre si: circularidade que retomando reedita, como acontece em outros contextos, na poesia de Guimaraens.

Como diria Octavio Paz (1993, p. 12), no mesmo texto: "O que chamamos de desenvolvimento nada mais é do que a aliança entre surpresa e recorrência, invenção e repetição, ruptura e continuidade". Paz (p. 28) talvez destacasse em Câmara ardente a ausência de linearidade no desenvolvimento, que discerniu entre poemas longos simbolistas: 
O poeta simbolista rompe a continuidade: acredita no valor da pausa e do espaço em branco. Um poema simbolista é um arquipélago de fragmentos. O desenvolvimento se atomiza. Diferentemente do poeta romântico, os fragmentos não estão unidos por uma cadeia verbal e sim por silêncios, afinidades, cores. A sucessão não é explícita e sim tácita. Por último, no poema simbolista abundam as metáforas e os símbolos enquanto se omitem as descrições e a narração. Encontro entre o extenso e o intenso: o poema longo se torna uma sucessão de momentos intensos.

Um tal raciocínio poderia nos levar ao exercício de percorrer as múltiplas correntes subterrâneas que ligam sonetos muito diversos entre si. Seja pelos olhares que são recorrentes, mas se alteram; seja pelas tonalidades cromáticas mais frequentes (que ora se turvam, ora se iluminam, ora se projetam para aqueles olhos e olhares, em cruzamento imagético); seja pelos ecos e ressonâncias internos aos versos para além das rimas e que recuperam algo que se perdeu; seja por versos tensos entre o que calam e o que enunciam; seja pela forma ritual que como ritual se apresenta enquanto violenta meio sem querer o que edificou... Mas não o faremos.

O soneto XII se abre com o verso: "Caiu sobre o teu corpo a última pá de terra", preparando o fechamento de um processo narrativo que elidiu (mas simultaneamente delineou) uma voz lírica tornada, a cada movimento, mais frágil. Nos desdobramentos do tempo e do espaço, nos versos ou vocábulos estratégicos que estabelecem pontos de articulação entre os diferentes momentos, ${ }^{10}$ essa voz reaparece nos tercetos que encerram o Soneto XII:

Outros dias virão cantando o mesmo hinário

E outras noites chorando o mesmo luar que sigo,

E onde vejo ondular o teu longo sudário...

Dentro de mim, porém, há de morrer, profundo,

O poente em funeral do teu olhar antigo,

Para não ressuscitar aqui no mundo...

(GUIMARAENS, 1960, p. 134)

10 Estudando, igualmente, o poema longo, em especial poemas de viagem, Mary-Ann Caws (1996, pp. 69-82) menciona elementos estruturadores como cortes (equivalentes formais dos capítulos para um romance, dos atos para uma peça, dos movimentos para um fragmento musical), sequências, pontos de articulação e espaços entre versos. Desenvolve, ainda, considerações sobre o papel desempenhado pelo ritmo (em seus diferentes modos de realização).

Remate de Males, Campinas-SP, v. 37, n. 1, pp. 9-36, jan./jun. 2017 
Como a pá de terra derradeira, os tercetos recaem sobre o poema, declarando sepultas também as imagens da amada, constituídas enquanto obsessões ou recorrências internas a uma eventual identidade subjetiva: as evocações da amada que nesse sujeito se encontram em processo de constante (re)atualização. Estaria completo, assim, o ritual em que a voz particular se perde, dissolvida no canto coletivo, que o poema final virá sublinhar. Ou não? Deslocadas as impressões subjetivas de uma dor assim particularizada e personalizada, os elementos formais que a configuram permanecem, contudo, compondo o conjunto. Como o compunham antes, na reduplicação exatamente das imagens obsedantes que acabavam por dispensar uma enunciação mais precisa do luto em descrição. Um luto que estava mais que reportado na abundância de formulações e reformulações em torno da morta, de sua enfermidade, de seu aspecto mortiço, dos pressentimentos e agouros que a envolviam.

"O poente em funeral de teu olhar antigo": forma esteticamente elaborada para algo que pode, infinitamente, ser declarado sepulto, ainda que não possa efetivamente ser jamais sepultado, a despeito de qualquer que seja o teor do que se declarou. Como ocorre com a liturgia formalizada no texto, também a subjetividade que nele se delineia só se constitui discursivamente, enquanto forma ficta, arremedo ficcional. O que seriam, então, em "Responsorium", poema conclusivo (e não derradeira oração), Alma, Corpo, Olhar, Lábio, Beijo, Cabelo e, enfim, Alma novamente? O que estava sepulto? O que não se pode sepultar?

Recitação coral e voz lírica, mais que se anularem mutuamente, estabelecem contrastes e contrapontos nos quais se relativizam as perspectivas que as constituem. E não parece possível aderir a uma dessas vozes se o conjunto do poema as constituiu em relação (em relação umas com as outras e com os vários elementos narrativos implicados). O que se declara sepulto surge reafirmado, eloquentemente, em uníssono, pela outra voz, que reaviva e faz oscilar uma Câmara ardente povoada de fantasmas. Em presença do amante enlutado, o coro (a que ele se une) encomenda o eterno descanso de um cadáver, que o conjunto das vozes as crispações derivadas de seus desencontros - não tem, contudo, o poder de efetivar.

Na fatura do poema, a relação com a estrutura narrativa implicitaria, por outro lado, relação igualmente tensionável com a forma litúrgica - a forma litúrgica submetida a distorção, a forma litúrgica imersa em uma contradição viva (o poema narrativo) que não lhe permite sacralidade ou 
estabilização. O poema, assim considerado, é conjunto a depender tanto da mescla quanto da integridade do resultado. Tudo isso nos reenviaria a projetos simbolistas de livros: sem defender efetivamente a total viabilidade teórica desse específico adjetivo, defenderia, a esta altura, que livros simbolistas e poemas simbolistas parecem aludir a objetos de que se podem derivar implicações sob diversos aspectos aproximáveis.

Sempre resta, no entanto, a possibilidade de indagar, no caso específico de Câmara ardente, se podemos pensar o conjunto menor por si (um composto formado por quatorze unidades) ou se parece mais coerente pensá-lo em relação a outra parte que, com o Setenário, compõe o livro por meio do qual Alphonsus de Guimaraens, depois de alguma experimentação e muita hesitação, declara-se publicamente apto a dar início a sua trajetória literária. O poema é o livro? Ou seria o livro pensável apenas pela relação entre um e outro poema?

\section{REFERÊNCIAS BIBLIOGRÁFICAS}

ANDRADE MURICY. Panorama do movimento simbolista brasileiro. 2⿳ㅗㄹ ed. 2v. Brasília: INL, 1962.

BAUDELAIRE, Charles. A modernidade. In: Poesia e prosa: volume único. Ed. organizada por Ivo Barroso (vários tradutores). Rio de Janeiro: Nova Aguilar, 1995.

BERNARDI, Mansueto. Vida e poesia de Eduardo Guimaraens. Porto Alegre: Globo, 1944.

CAMARGOS, Marcia. Villa Kyrial: crônica da Belle Époque paulistana. São Paulo: SENAC, 2001.

CAROLLO, Cassiana Lacerda. Documentos: um apêndice à obra completa de Alphonsus de Guimaraens. Estudos brasileiros, Curitiba, v. 2, no 3, 1977, p. 191.

CAROLLO, Cassiana Lacerda. Decadismo e simbolismo no Brasil: crítica e poética. 2 v. Rio de Janeiro: Livros Técnicos e Científicos / Brasília: Instituto Nacional do Livro, 1980-1981.

CAWS, Mary-Ann. Poème long, poème court: le sujet en cloture. In: RABATÉ, Dominique; SERMET, Joëlle de; VADÉ, Yves. Modernités 8: Le sujet lyrique en question. Bordeaux: Presses Universitaires de Bordeaux, 1996.

COMBE, Dominique. Poésie et récit: une rhétorique des genres. Paris: José Corti, 1989.

COMBE, Dominique. Les genres littéraires. Paris: Hachette, 1992. 
COMBE, Dominique. Aimé Césaire et "la quête dramatique de l'identité". In: RABATÉ, Dominique; SERMET, Joëlle de; VADÉ, Yves. Modernités 8: Le sujet lyrique en question. Bordeaux: Presses Universitaires de Bordeaux, 1996.

SERMET, Joëlle de; VADÉ, Yves. Modernités 8: Le sujet lyrique en question. Bordeaux: Presses Universitaires de Bordeaux, 1996.

SERMET, Joëlle de; VADÉ, Yves. L'épopée à l'époque moderne. In: PEDROSA, Celia; ALVES, Ida (org.). Subjetividades em devir: estudos de poesia moderna e contemporânea. Rio de Janeiro: 7 Letras, 2008, pp. 51-62.

DUTRA, Waltensir \& CUNHA, Fausto. Biografia crítica das letras mineiras: esboço de uma história da literatura de Minas Gerais. Rio de Janeiro: Instituto Nacional do Livro, 1956.

GUIMARAENS, Alphonsus de. Salmos da noite. Um caderno de Alphonsus. A manhã, Rio de Janeiro, 8 nov. 1942. Autores e livros, ano 2, v. 3, no 13, pp. 210, 211 e 218.

GUIMARAENS, Alphonsus de. Obra completa. Rio de Janeiro: Aguilar, 1960.

GUIMARAENS FILHO, Alphonsus de. O manuscrito de Câmara ardente. O Diário, Suplemento literário, Belo Horizonte, 2 ago. 1953, p. 2.

GUIMARAENS, Eduardo (1910). Discurso sobre a arte. In: SILVA, Maria Luiza Berwanger da. Paisagens reinventadas: traços franceses no simbolismo sul-rio-grandense. Porto Alegre: Ed. Universidade UFRGS, 1999, pp. 305-307.

LINS, Vera. Livro simbolista, o livro a mais. In: SUSSEKIND, Flora \& DIAS, Tânia (org.). A historiografia literária e as técnicas da escrita. Rio de Janeiro: Edições Casa de Rui Barbosa; Vieira e Lent, 2004, pp. 489-495.

LISBOA, Henriqueta. A poesia de Alphonsus de Guimaraens. Revista do livro, Órgão do INL/MEC, Rio de Janeiro, ano XIII, no 41, 2o trimestre 1970, pp. 22-30.

PAZ, Octavio. Cantar e contar (sobre o poema extenso). In: A outra voz. Trad. Waldir Dupont. São Paulo: Siciliano, 1993, pp. 11-31.

PEIXOTO, Sérgio Alves. A consciência criadora na poesia brasileira: do barroco ao simbolismo. São Paulo: Annablume, 1999.

SILVA, Maria Luiza Berwanger da. Paisagens reinventadas: traços franceses no simbolismo sul-rio-grandense. Porto Alegre: Ed. Universidade UFRGS, 1999.

VERAS, Eduardo Horta Nassif. O oratório poético de Alphonsus de Guimaraens. Uma leitura do Setenário das Dores de Nossa Senhora. Belo Horizonte: Relicário edições, 2016. 